\title{
PENYULUHAN KELOMPOK TANI BAYAN TENTANG ASAM HUMAT TERIMOBIL DALAM RUMPUT LAUT SEBAGAI PELENGKAP PUPUK
}

\author{
Dhony Hermanto ${ }^{1,3)}$, Nurul Ismillayli1), Fahrurazi ${ }^{2}$, Nurlaela²), Ahmad Wirahadi2), Ulul Khairi Zuryati3), \\ Ruru Honiar ${ }^{3)}$, I G. Ayu Sri Andayani3), Baiq Mariana ${ }^{3)}$ \\ 1)Program Studi Kimia, Fakultas Matematika dan IImu Pengetahuan Alam, Universitas Mataram, Mataram, \\ Nusa Tenggara Barat 83125 Indonesia \\ 2)Laboratorium Kimia Dasar, Fakultas Matematika dan IImu Pengetahuan Alam, Universitas Mataram, Mataram, \\ Nusa Tenggara Barat 83125 Indonesia \\ ${ }^{3}$ Laboratorium Kimia Analitik, Fakultas Matematika dan IImu Pengetahuan Alam, Universitas Mataram, Mataram, \\ Nusa Tenggara Barat 83125 Indonesia \\ Corresponding author : Nurul Ismillayli \\ E-mail : nurul.ismillayli@unram.ac.id
}

\section{Diterima Oktober 2020, Disetujui Oktober 2020}

\begin{abstract}
ABSTRAK
Asam humat telah diketahui memiliki dampak tidak langsung dalam perbaikan kualitas tanah di lahan kering, akan tetapi harga asam humat dalam jumlah banyak yang relatif tinggi tidak dapat dijangkau oleh petani. Hal ini yang mendorong pemanfaatan teknik modifikasi yang dapat mengurangi jumlah pemakaian asam humat tanpa mengurangi manfaatnya, yaitu dengan mengimobilisasi asam humat pada suatu material pendukung seperti rumput laut. Kegiatan pengabdian ini berupa penyuluhan kepada mitra tentang penerapan asam humat terimobil dalam rumput laut sebagai pelengkap pupuk yang dapat meningkatkan produktivitas tanah sehingga potensi lahan kering sebagai lahan pertanian meningkat. Mitra kegiatan adalah Kelompok Tani jagung "SBP 212" dan UPTD Dinas Pertanian Perkebunan Kelautan Kehutanan dan Perikanan (DPPKKP) Kec. Bayan. UPTD DPPKKP Kec. Bayan juga berperan dalam difusi Ipteks dan sebagai motor penggerak untuk menyebarkan kegiatan kepada anggota kelompok tani sasaran lainnya sehingga kegiatan dapat berkelanjutan. Keberlanjutan kegiatan diharapkan dapat terjaga untuk peningkatan potensi lahan kering sebagai lahan pertanian produktif yang ditandai dengan peningkatan produktivitas tanaman.
\end{abstract}

Kata kunci: penyuluhan; asam humat; rumput laut; pelengkap pupuk; lahan kering.

\begin{abstract}
Humic acid is known to have an indirect impact on improving soil quality in dry land, however, the price of humic acid in large quantities is too expensive for farmers. It was important to use of modified techniques that can reduce the amount of humic acid used without reducing its benefits, namely by immobilizing humic acid in a supporting material such as seaweed. The service activity, counseling to farmer group about application of immobilized humic acid in seaweed as fertilizer complement to increase soil productivity so that dry land as potential agricultural land increases. The partner of the activity is the "SBP 212" Corn Farmer Group and UPTD Department of Agriculture, Plantation, Marine, Forestry and Fisheries (DPPKKP) Kec. Bayan. UPTD DPPKKP Kec. Bayan also plays a role in science and technology diffusion and as mediator to disseminate the activities to other target farmer group members for sustainability of activity. It is expected that the sustainability of activities can be maintained to increase dry land uses as productive agricultural land that indicated by increasing of plant productivity.
\end{abstract}

Keywords: counseling; humic acid; seaweed; fertilizer supplement; dry land.

\section{PENDAHULUAN}

Nusa Tenggara Barat (NTB) merupakan salah satu provinsi pendukung pangan nasional. Potensi strategis sumber daya alam dan sumber daya manusia yang dimiliki NTB diharapkan dapat mendukung pembangunan ekonomi Indonesia. Dengan luas wilayah $20.153,15 \mathrm{~km}^{2}$, NTB didominasi lahan potensial yaitu $84,19 \%$ yang berupa lahan kering. Kabupaten Lombok Utara memiliki $\pm 38.000 \mathrm{Ha}$ lahan kering dengan pemanfaatan untuk tanaman pangan diantaranya jagung dan ubi kayu (BPS, 2019a). Salah satu daerah administratif pemerintahan Kabupaten Lombok Utara adalah Kecamatan Bayan. Daerah ini sebagian besar wilayahnya memiliki ciri kondisi agroklimat yang relatif kering dengan intensitas curah hujan rendah (Mulyani, Nursyamsi, \& Las, 2014), tidak terdapat sarana irigasi (Idjudin \& Marwanto, 
2008; Notohadiprawiro, 2006) dan memiliki agregat tanah yang kurang mantap (Suwardji, Utomo, \& Sukartono, 2012). Kondisi tanah lahan kering menyebabkan tanah sulit didayagunakan atau penggunaannya sangat terbatas. Diperlukan strategi dan komitmen dalam mengoptimalisasi lahan kering yang mampu meningkatkan produktivitas tanaman.

Penambahan bahan organik sebagai pelengkap pupuk seperti asam humat yang memiliki kapasitas tukar kation (KTK) tinggi (Sembiring, Wawan, \& Khoiri, 2015) diketahui dapat mengontrol pelepasan nutrien di dalamnya secara perlahan, sehingga dapat meningkatkan produktivitas tanaman dan ramah terhadap lingkungan. Telah diketahui bahwa asam humat sebagai bahan organik merupakan sumber karbon dan nitrogen (Ismillayli, Kamali, Hamdiani, \& Hermanto, 2019), meningkatan efektifitas pemupukan (Hartatik, Husnain, \& Widowati, 2015), perkembangan dan pengambilan nutrisi makro dan mikro tanaman (Hermanto, Dharmayani, Kurnianingsih, \& Kamali, 2013) serta berdampak tidak langsung pada peningkatan sifat kualitas tanah meliputi aerasi, aggregasi, kapasitas menahan air, permeabilitas, transport dan ketersediaan makro/mikronutrien (Hermanto, Kamali, Kurnianingsih, \& Ismillayli, 2013).

Daya beli petani di lahan kering masih rendah sehingga harga asam humat dalam jumlah banyak yang relatif tinggi tidak dapat terjangkau bagi petani. Diperlukan suatu teknik modifikasi yang dapat mengurangi jumlah pemakaian asam humat tanpa mengurangi manfaatnya. Salah satunya adalah mengimobilisasi asam humat pada suatu padatan pendukung yang juga dapat menyerap dan menyimpan air serta merupakan potensi lokal yang banyak tersedia seperti rumput laut. Rumput laut banyak dibudidayakan masyarakat setempat dan belum dimanfaatkan secara optimal. Rumput laut mengandung gelatin dan polisakarida yang dapat menyerap dan menyimpan air. Selain itu telah banyak penelitian yang membuktikan peranan positif rumput laut sebagai pupuk yang dapat meningkatkan pertumbuhan dan hasil panen (Dhony Hermanto et al., 2020). Rumput laut mengandung asam alginat, polifenol, asam amino bebas dan fitohormon seperti auksin dan sitokinin (Dalero, Gerung, Ngangi, Lumingas, \& Lasut, 2019) yang dapat meningkatkan pertumbuhan akar dan vitalitas tanaman serta menstimulasi produksi zat hijau daun yang berperan dalam fotosintesis (Viqar, Ehteshamul-haque, Ara, \& Athar, 2005). Pada penelitian lainnya ditemukan pentingnya peranan sitokinin rumput laut dalam meningkatkan resistensi tanaman terhadap penyakit dan nematoda (Bai, Banu, Prakash, \& Goldi, 2007).

Pada kegiatan pengabdian ini penyuluhan dalam pengaplikasian asam humat terimobil dalam rumput laut sebagai pelengkap pupuk pada lahan pertanian tanaman jagung di lahan pertanian mitra (kelompok tani jagung di Kec. Bayan). Diharapkan kegiatan penyuluhan ini mudah diterima dan diaplikasikan oleh mitra yang memiliki keterbatasan pendidikan dengan rata-rata lama sekolah 6,19 tahun dan sebagian besar merupakan masyarakat kurang mampu secara ekonomi (BPS, 2019b), sehingga keberlangsungan kegiatan dapat terpelihara. Penerapan asam humat terimobil dalam rumput laut sebagai pelengkap pupuk pada kondisi optimum dapat meningkatkan ketersediaan dan pengambilan makro/mikro nutrien sehingga menghasilkan hasil panen yang lebih besar terutama tanaman jagung di Kec. Bayan.

\section{METODE}

Kegiatan pengabdian kepada masyarakat ini dilakukan pada lahan milik mitra yaitu kelompok tani jagung "SBP 212" dibantu oleh UPTD Dinas Pertanian Perkebunan Kelautan Kehutanan dan Perikanan (DPPKKP) Kec. Bayan sebagai wadah pendidikan masyarakat dalam hal difusi ipteks (penerima alih teknologi) dan sebagai motor penggerak untuk menyebarkan luaskan kepada anggota kelompok tani sasaran lainnya agar kegiatan dapat berkelanjutan. Melalui kegiatan penyuluhan tentang penerapan asam humat terimobil dalam rumput laut sebagai pelengkap pupuk pada tanaman jagung di lahan pertanian kering Kec. Bayan dapat meningkatkan produktivitas tanaman tersebut.

Tahapan-tahapan yang akan dilakukan dalam melaksanakan solusi yang telah ditawarkan adalah Focus Group Discussion (FGD), penyuluhan dan praktek atau demonstrasi. Mitra kegiatan pengabdian di Kec. Bayan dapat berperan aktif pada transfer ipteks dalam hal teknologi penerapan asam humat terimobil dalam rumput laut sebagai pelengkap pupuk untuk diaplikasikan pada tanaman jagung lahan pertanian kering Kec. Bayan. Pelaksanaan kegiatan pengabdian kepada masyarakat berupa penyuluhan kelompok tani Bayan dibagi 2 tahapan yaitu:

1. FGD dan penyuluhan

Pada tahap awal disebarkan kuisioner yang diisi oleh mitra untuk mendapatkan gambaran tingkat pengetahuan tentang manfaat penerapan asam humat terimobil dalam rumput laut sebagai pelengkap pupuk. Terdapat 10 pertanyaan yang harus dijawab dengan point nilai tertinggi adalah empat dan 
terendah adalah satu. Nilai maksimal yang diperoleh koresponden adalah $40(4 \times 10)$ dan minimal $10 \quad(1 \times 10)$. Kriteria tingkat pengetahuan yang diperoleh masing-masing responden dapat dikelompokkan dalam kategori baik bila nilai responen $\geq 31-40$; sedang bila nilai responden $\geq 21-30$; dan kurang bila nilai responden 10-20.

Kegiatan FGD dilanjutkan dengan sosialisasi tentang peranan asam humat terimobil dalam rumput laut, dampak langsung dan tak langsung pada tanah dan tanaman serta bagaimana pengaplikasian agar didapatkan hasil yang optimum. Sebagai penutup FGD, sesi tanya jawab dilakukan untuk memperjelas materi yang kurang dipahami peserta.

\section{Tahap praktek atau demonstrasi}

Pada tahap praktek atau demonstrasi ini dilakukan pendampingan mitra tentang preparasi asam humat terimobil dalam rumput laut yang dilakukan dengan dua teknik yang berbeda, yaitu teknik entrapment (gel) dan covalent bending (liquid). Asam humat terimobil dalam rumput laut ini selanjutnya digunakan sebagai pelengkap pupuk. Pengolahaan lahan dengan diberi pupuk organik $\left(20 \mathrm{~kg} \mathrm{ha}^{-1}\right)$ dan asam humat terimobil dalam rumput laut dengan perbandingan komposisi optimum. Penanaman bibit jagung dilakukan dengan memvariasi beberapa jarak tanam. Tanaman jagung yang dipilih adalah varietas lokal. Pemberian pupuk dengan dosisi $1 / 3$ bagian pupuk organik dan pelengkap pupuk (asam humat terimobil dalam rumput laut diberikan dalam larikan di samping barisan tanaman jagung pada saat tanam. Selanjutnya pemberian pupuk dengan dosis $2 / 3$ bagian pupuk organik dan asam humat terimobil dalam rumput laut diberikan bersamaan dengan penyemprotan $0,1 \%$ asam humat saat tanaman berumur 30 HST (hari setelah tanam). Pemberian asam humat terimobil dalam rumput laut pada lahan dilakukan bersamaan dengan pemupukan.

\section{HASIL DAN PEMBAHASAN}

Berdasarkan kajian sebelumnya (Hermanto, Kamali, Kurnianingsih, \& Ismillayli, 2013) lahan pertanian Kec. Bayan merupakan lahan kering dengan ciri fisik merupakan tanah pasiran dengan bagian dominan tanah ini merupakan fraksi pasir dengan tekstur kasar, dan struktur lepas menjadikan tanah ini memiliki permeabilitas sangat cepat dan kapasitas dalam mengikat air rendah. Sedangkan ciri secara kimia memiliki kadar makro/mikronutrien antara lain: C-organik, N-kjehdahl, P-total, logam K, logam Zn, logam Fe, kapasitas tukar kation (KTK) dan $\mathrm{pH}$.
Kadar C-organik rendah menunjukkan bahwa tanah memiliki fraksi bahan organik rendah. Fraksi ini bersama dengan lempung bertanggung jawab terhadap sifat fisikokimia tanah misalnya kapasitas tanah dalam menahan air dan proses-proses kimia dalam tanah meliputi pertukaran ion, oksidasi reduksi termasuk efisiensi pemupukan. Kandungan koloid rendah menyebabkan pemupukan $\mathrm{N}$ pada jenis tanah ini kurang efisien, hal ini disebabkan oleh pelindian (leaching). Efek pelindian juga disebabkan oleh rendahnya nilai KTK (Tabel 1) tanah yang terukur. Kadar fosfor ( $P$ total) sangat berbeda pada kedalaman $0-20$ $\mathrm{cm}$ dan 21-40 cm. Warna fisik tanah seperti ditunjukkan Gambar 1 pada kedua lapisan tersebut adalah berbeda, biasanya lapisan atas memiliki warna lebih muda karena teroksidasi oleh udara. Derajat keasaman tanah pada $\mathrm{pH}$ netral $(6,97$ dan 6,80$)$.

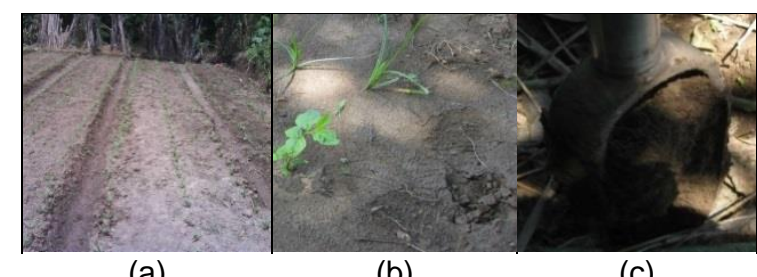

(a)

(b)

(c)

Gambar 1. Warna fisik tanah lahan kering (a) lahan pertanian Kec. Bayan; (b) kedalaman $0-20 \mathrm{~cm}$ (c) $21-40 \mathrm{~cm}$.

Pembuatan pelengkap pupuk dilakukan dengan mengimobilisasi asam humat ke dalam rumput laut melalui teknik entrapment (gel) dan covalent bending (liquid). Asam humat dan rumput laut merupakan polielekrolit, apabila direaksikan pada kondisi yang tepat dapat berinteraksi satu sama lain melalui gugus karboksil dan gugus amina. Asam humat sebagai material aktif terperangkap dalam rumput laut pada rantai polimer polisakaridanya, sehingga diharapkan dapat memberikan aplikasi yang lebih baik dari pada asam humat tanpa imobilisasi. Asam humat dalam bentuk bulk material terimobil pada material pendukung maka sisi aktif dari asam humat diharapkan lebih efektif dalam berinteraksi dengan unsur hara. Unsur hara makro pada tanah dengan tekstur berpasir sedikit terserap oleh tanaman, hal ini dimungkinkan unsur hara tersebut terbawa oleh air atau menguap. Aplikasi asam humat terimmobil pada rumput laut terbukti meningkatkan efisiensi pemupukan dengan nilai tertinggi didapat pada pemberian pupuk organik dan $0,1 \%$ asam humat terimobilisasi pada rumput laut sebagai pelengkap pupuk sebanyak $20 \mathrm{~kg} \mathrm{ha}^{-1}$ (gel) dan $0,1 \%$ asam humat terimobilisasi pada rumput laut (liquid). 
Kegiatan pengabdian kepada masyarakat ini diawali dengan sosialisasi tentang teknologi imobilisasi asam humat pada material pendukung berupa rumput laut. Pada kegiatan ini dilakukan FGD dan pengisian kuisioner oleh peserta untuk mengetahui tingkat pengetahuan awal peserta mengenai teknologi imobilisasi asam humat pada material pendukung berupa rumput laut yang digunakan sebagai pelengkap pupuk. Kegiatan FGD dilanjutkan dengan penyuluhan. Metode yang digunakan adalah ceramah tentang teknologi imobilisasi asam humat pada material pendukung berupa rumput laut sebagai pelengkap pupuk. Penyuluhan dilakukan dengan tayangan visual agar peserta mudah memahami materi yang disampaikan. Pada sesi akhir diadakan diskusi tentang hal-hal yang belum dipahami oleh peserta. Selain itu para peserta diberi kesempatan untuk melakukan diskusi antar peserta dan pemateri tentang pemahaman materi yang disampaikan. Para peserta sangat antusias karena mendapatkan pengetahuan baru teknologi imobilisasi asam humat pada material pendukung berupa rumput laut sebagai pelengkap pupuk.

Kegiatan penyuluhan dilanjutkan dengan kerja praktek atau demonstrasi teknologi imobilisasi asam humat pada material pendukung berupa rumput laut sebagai pelengkap pupuk. Sosialisasi dan penyuluhan hasil penerapan pelengkap pupuk pada tanaman jagung dilakukan melalui upaya pemberian pemahaman dan pengetahuan tentang pengaruh asam humat terimobil dalam rumput laut sebagai sebagai pelengkap pupuk organik terhadap produktivitas tanaman jagung di lahan kering Kec. Bayan. Selanjutnya dilakukan praktik masing-masing kegiatan di Kelompok Tani jagung di Kec. Bayan seperti terlihat pada Gambar 2. Terdapat sekitar 20 kelompok tani di Kec. Bayan, akan tetapi praktik kegiatan dilakukan di lahan pertanian milik salah satu kelompok tani "SPB 212" yang memiliki sumur bor dan pompa air. Sistem pertanian di Kec. Bayan mengandalkan air hujan sementara penanaman jagung dilakukan pada musim kemarau sehingga dibutuhkan pengairan tambahan yang berasal dari sumur bor. Kondisi di lapangan menunjukkan tidak semua kelompok tani memiliki sumur bor dan pompa. Oleh karenanya praktik tidak dilakukan di semua lahan kelompok tani. Akan tetapi, diharapkan kelompok tani SPB 212 dapat membimbing kelompok tani lain sehingga hasil kegiatan pengabdian ini dapat berkelanjutan.

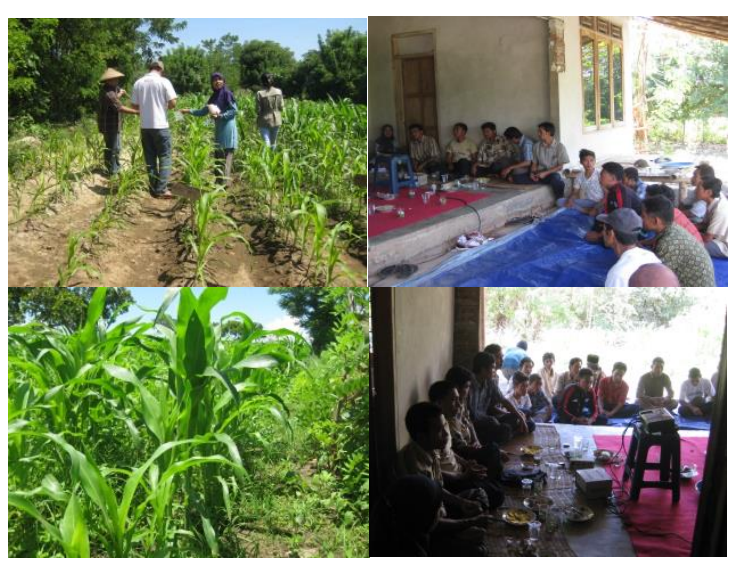

Gambar 2. Demonstrasi dan penyuluhan kegiatan pada kelompok tani jagung Bayan

Kegiatan kerja praktek atau demonstrasi kemudian dilanjutkan dengan pengisian kuisioner untuk mengukur tingkat pemahaman dan pengingkatan pengetahuan peserta setelah diberikan pengetahuan dan keterampilan tentang pengolahan teknologi imobilisasi asam humat pada material pendukung berupa rumput laut sebagai pelengkap pupuk. Peningkatan pengetahuan ditampilakan secara kuantitatif pada Gambar 3. Terjadi peningkatan pengetahuan peserta mengenai pengolahan teknologi imobilisasi asam humat pada material pendukung berupa rumput laut sebagai pelengkap pupuk yang ditandai dengan meningkatnya persentase responden berkriteria pemahaman baik dan sedang dan menurunnya persentase responden berkriteria pemahaman kurang.

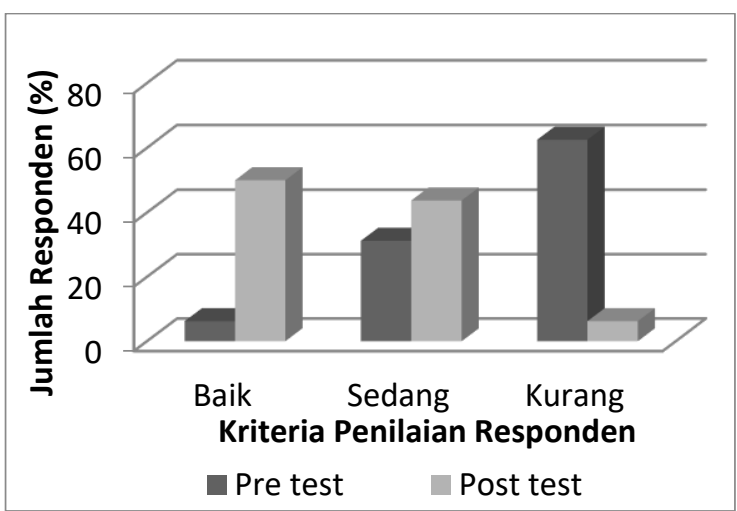

Gambar 3. Perbandingan tingkat pemahaman peserta kegiatan penyuluhan

\section{SIMPULAN DAN SARAN}

Kegiatan pengabdian berupa penyuluhan dan praktek kerja dapat meningkatkan pengetahuan dan keterampilan kelompok-kelompok tani Kec. Bayan tentang teknologi imobilisasi asam humat pada material pendukung sepertit rumput laut untuk digunakan sebagai pelengkap pupuk. Respon mitra terhadap kegiatan sangat baik sekali 
ditunjukkan dengan partisipasi aktif peserta selama kegiatan pengabdian berlangsung.

\section{DAFTAR RUJUKAN}

Bai, N. R., Banu, N. R. L., Prakash, J. W., \& Goldi, S. J. (2007). Effects of Asparagopsis taxiformis extract on the Growth and Yield of Phaseolus aureus. Journal of Basic and Applied Biology. 1(1). 6-11.

BPS. (2019a). Kecamatan Bayan dalam angka. Badan Pusat Statistik Kabupaten Lombok Utara, p. 69.

BPS. (2019b). Statistik kesejahteraan rakyat Kabupaten Lombok Utara 2019. Badan Pusat Statistik Kabupaten Lombok Utara, p. 19.

Dalero, M. D., Gerung, G. S., Ngangi, E. L. A., Lumingas, L. J. L., \& Lasut, M. T. (2019). Kultur in vitro rumput laut Kappaphycus alvarezii dengan formulasi zpt (zat pengatur tumbuh) dan wadah yang berbeda. Jurnal Ilmiah Platax. 7(1). 274-283.

Hartatik, W., Husnain, \& Widowati, L. R. (2015). Peranan Pupuk Organik dalam Peningkatan Produktivitas Tanah dan Tanaman. Jurnal Sumberdaya Lahan. 9(2).107-120.

Hermanto, D., Dharmayani, N. K. T., Kurnianingsih, R., \& Kamali, S. R. (2013). Pengaruh asam humat sebagai pelengkap pupuk terhadap ketersediaan dan pengambilan nutrien pada tanaman jagung di lahan kering Kec.Bayan-NTB. Jurnal IImu Pertanian. 16(2). 28-41.

Hermanto, D., Ismillayli, N., Fahrurazi, F., Wirahadi, A., Honiar, R., Andayani, I. G. A. S., \& Shofiyana, L. M. (2020). Pendampingan masyarakat desa jago lombok tengah dalam pemanfaatan limbah rumput laut sebagai pupuk. Jurnal Masyarakat Mandiri. 4(4). 6-9.

Hermanto, D., Kamali, S. R., Kurnianingsih, R., \& Ismillayli, N. (2013). Optimalisasi lahan kering kecamatan bayan-lombok utara menggunakan asam humat terimmobil dalam rumput laut sebagai pelengkap pupuk pada tanaman jagung (zea mays L). Sains Tanah-Jurnal IImu Tanah Dan Agroklimatologi. 10(2). 101-112.

Idjudin, A. A., \& Marwanto, S. (2008). Reformasi pengelolaan lahan kering untuk mendukung swasembada pangan. Jurnal Sumberdaya Lahan. 2(2). 115125.
Ismillayli, N., Kamali, S. R., Hamdiani, S., \& Hermanto, D. (2019). Interaksi asam humat dengan larutan urea, sp36 dan $\mathrm{KCl}$ dan pengaruhnya terhadap efisiensi pemupukan. Jurnal Pijar MIPA. 14(1). 77-81.

Mulyani, A., Nursyamsi, D., \& Las, I. (2014). Percepatan pengembangan pertanian lahan kering iklim kering di Nusa Tenggara. Jurnal Pengembangan Inovasi Pertanian. 7(4). 187-198.

Notohadiprawiro, T. (2006). Pertanian lahan kering di indonesia: potensi, prospek, kendala dan pengembangannya. Repro: IImu Tanah. 2006. 1-15.

Sembiring, I. S., Wawan, \& Khoiri, M. A. (2015). Sifat kimia tanah dystrudepts dan pertumbuhan akar tanaman kelapa sawit (elaeis guineensis jacq.) yang diaplikasi mulsa organik mucuna bracteata. JOM Faperta. 2(2). 1-11.

Suwardji, Utomo, W. H., \& Sukartono. (2012). Tanah lempung berpasir pada pertanaman jagung. Buana Sains. 12(1). 61-68.

Viqar, S., Ehteshamul-haque, S., Ara, J., \& Athar, M. (2005). Comparative efficacy of brown, green and red seaweeds in the control of root infecting fungi and okra Comparative efficacy of brown , green and red seaweeds in the control of root infecting fungi and okra. International Journal of Environmental Science and Technology. 2(2). 129132. 